\title{
A NOTE ON SIMULTANEOUSLY DIAGONALIZABLE MATRICES
}

\author{
ABRAHAM BERMAN $^{1}$ AND ROBERT J. PlemMONS ${ }^{2}$
}

Abstract. Consider the functional $f(U)=\sum_{i=1}^{n} \max _{j}\left\{\left(U^{T} M_{j} U\right)_{i i}\right\}$ over orthogonal matrices $U$, where the collection of $n$-by- $n$ symmetric matrices $M_{j}$ are pairwise commutative, and thus simultaneously diagonalizable. Selecting an orthogonal matrix $U$ which maximizes $f(U)$ has applications in adaptive optics. A proof is given here that any orthogonal matrix $Q$ which simultaneously diagonalizes the $M_{j}$ maximizes the function $f$.

Mathematics subject classification (1991): 15A27, 15A45, 15A51, 15A90. mization.

Key words and phrases: Simultaneous diagonalization, commutativity, adaptive optics, trace maxi-

\section{REFERENCES}

[1] A. Berman and R. J. Plemmons, Nonnegative Matrices in the Mathematical Sciences, 2nd Edition, SIAM Press Classics Series no. 9, Philadelphia, 1994.

[2] A. Bunse-Gerstner, R. BYers, AND V. MeHRMANN, Numerical methods for simultaneous diagonalization, SIAM. J. Matrix Anal. and Applic., 14 (1993), 927-949.

[3] B. D. FLURY AND B. E. NEUENSCHWANDER, Simultaneous diagonalization algorithms with applications in multivariate statistics, in Approximation and Computation (R. Zahar, ed.), pp. 179-205, Basel: Birkhauser, 1995.

[4] J. W. HARDY, Adaptive optics, Scientific American, 270, no. 6, June (1994), 60-65.

[5] R. Horn AND C. Johnson, Matrix Analysis, Cambridge University Press, Cambridge, England, 1985.

[6] J. Nelson, Reinventing the telescope, Popular Science, 85, January (1995), 57-59.

[7] R. A. SMith, Seeing the universe through new eyes, National Geographic Magazine, 185, no. 1, January (1994), 2-41. 